\title{
Application of ISSR markers for study of genetic polymorphism of dark grain maize varieties
}

\author{
L.S. Valiyeva*, G.K. Rahimova, N.A. Nabiyeva \\ Genetic Resources Institute of the National Academy of Sciences of Azerbaijan, Baku, Azerbaijan
}

DOI 10.18699/ICG-PlantGen2019-10

(c) Autors, 2019

*e-mail: I.valiyeva@yandex.ru

\begin{abstract}
The grain of maize (Zea mays L.) can accumulate anthocyanins pigments belonging to the flavonoid groupings and possessing health benefits (antioxidant, antimicrobial, anti-carcinogenic). Numerous studies have found that regular consumption of food rich in anthocyanins leads to a significant decrease in the risk of diabetes, obesity, cardiovascular and oncological diseases. The combination of the nutritional and therapeutic values of the beneficial anthocyanins of maize is the main feature of the functional product. In this regard, breeding programs for increasing the content of anthocyanins in the grains become relevant. As a starting material, the genetic diversity of 38 maize samples with dark colored grains from the collection of the National Genbank of Azerbaijan was studied using 6 ISSR primers. On average, the level of polymorphism for all primers was $94.6 \%$, and the average value of the genetic diversity index was 0.92 . The high level of genetic variability of the dark grain maize varieties is a successful platform for the selection of promising genotypes in this direction of selection.
\end{abstract}

Key words: maize anthocyanins; functional product; genetic diversity; ISSR analysis.

\section{1. İntroduction}

Maize (Zea mays L.) is an important cultivated cereal, the most common in world agriculture. It is a valuable food and technical plant, from which more than 500 main products and by-products have been obtained (Tsikov, 2003). Among other useful matters are dark-colored pigments - anthocyanins - which give the corresponding color to plant organs and possess high antioxidant, antimicrobial and anticarcinogenic properties. They accumulate to a high degree in leaves, stem and grains of certain forms of maize (Tretyakov et al., 2012; Adzhieva et al., 2015). Numerous epidemiological studies from different countries have established that regular consumption of food plants rich in anthocyanins leads to a significant decrease in many chronic diseases, such as diabetes, obesity, cardiovascular and oncological diseases. The properties of beneficial anthocyanins that reduce the risk of developing diseases and promote human health have been scientifically substantiated and confirmed (Fukamachi et al., 2008; Tsuda, 2012; Lago et al., 2013; Khlestkina, 2013.) Thus, along with the nutritional value, the combination of therapeutic and preventive properties of the dark-grain forms of maize allows their use as a functional food (Rodriguez et al., 2013; Petroni et al., 2014; Dolmatova et al., 2016). In this connection, the directions of breeding for increasing the content of anthocyanins in the grains of maize are relevant. For the selection of valuable genotypes, their characterization and assessment using molecular technologies are important, which significantly reduces costs and time for developing hybrid combinations in breeding schemes (Khavkin, 2003). Highly informative ISSR markers have been successfully used to analyze the genetic diversity of maize (Sivolap et al., 2001; Barakat et al., 2009; Salah et al., 2016). The purpose of this study was to assess the genetic diversity of samples of dark grain maize, including self-pollinated lines and hybrids from the collection of the National Genebank of Azerbaijan, using ISSR markers.

\section{Materials and methods}

The studies were carried out in the Laboratory of Biotechnology of the Genetic Resources Institute (GRI of the National Academy of Sciences of Azerbaijan) in 2015-2019. The study object was seeds of 38 local dark-grain samples of maize from 3 varieties, 25 inbred lines, 10 interline, inter-variety and variety-linear hybrids. Total DNA was extracted from the leaves of maize using the modified CTAB method (Doyle et al., 1987). The concentration and quality of DNA was determined by a spectrophotometric method using a Nanodrop tester (Thermo Scientific, 2000). The concentration of DNA solutions for PCR was $50 \mathrm{ng} / \mathrm{mkl}$. As a result of preliminary studies, 6 primers were selected from 14 ISSR markers for the analysis, synthesizing clearly visible polymorphic allelesamplicons. The reaction mixture of ISSR-PCR with a volume of $20 \mathrm{mkl}$ included: DNA of the analyzed sample $(2 \mathrm{mkl})$, primer (Integrated DNA Technologies) $(0.2 \mu \mathrm{M})$, mixture of deoxyribonucleotides of 4 types (Bioline) $(0.2 \mu \mathrm{M}$ of each), 10x PCR buffer $(0.2 \mu \mathrm{M}), \mathrm{MgCI} 2(1.5 \mathrm{mM})$, Taq DNA polymerase (1 unit) (all reagents are from SinaClon Bioscience) and distilled water until the given volume was reached. PCR was performed in the following mode: initial denaturation at $94{ }^{\circ} \mathrm{C}$ for $5 \mathrm{~min} ; 35$ cycles: denaturation at $94^{\circ} \mathrm{C}$ for $1 \mathrm{~min}$, hybridization at the melting temperature of the primer for 1 min, elongation at $72{ }^{\circ} \mathrm{C}$ for $2 \mathrm{~min}$, and final elongation at $72{ }^{\circ} \mathrm{C}$ for $7 \mathrm{~min}$. The detection of PCR products was carried out by electrophoresis in a $1.5 \%$ agarose gel with the addition of ethidium bromide ( $4 \mathrm{mkl} / 100 \mathrm{ml}$ of gel), in 1xTAE-buffer at $\mathrm{pH}-8.0$ for $50 \mathrm{~min}$ at a voltage of $120 \mathrm{~V}$. Amplicons after electrophoresis were visualized in a transilluminator (Bio-Rad) by irradiating gels in ultraviolet rays and analyzed by the intensity of the glow of the complexes of ethidium bromide with DNA.

The marker for determining the size of the amplified fragments was a 100-bp DNA ladder. For registration of the presence (1) or the absence (0) of fragments with the same molecular weight, we prepared binary matrices for each gel. 
Table 1

List of ISSR markers and their polymorphism

\begin{tabular}{|c|c|c|c|c|c|c|}
\hline \multirow{2}{*}{ Primer name } & \multirow{2}{*}{$\begin{array}{l}\text { Sequence } \\
5^{\prime} \rightarrow 3^{\prime}\end{array}$} & \multicolumn{2}{|c|}{ Number of bands } & \multirow{2}{*}{$\begin{array}{l}\text { Polymorphism } \\
\%\end{array}$} & \multirow{2}{*}{$\mathrm{H}$} & \multirow{2}{*}{$\mathrm{PIC}$} \\
\hline & & poly & mono & & & \\
\hline A1 & (AG)8T & 11 & 0 & 100 & 0.95 & 0.29 \\
\hline A5 & $(\mathrm{GAA}) 6$ & 16 & 2 & 88.8 & 0.91 & 0.37 \\
\hline UBC812 & (GA) $8 \mathrm{~A}$ & 8 & 1 & 88.8 & 0.90 & 0.35 \\
\hline UBC817 & (CA) $8 \mathrm{~A}$ & 7 & 0 & 100 & 0.93 & 0.38 \\
\hline UBC823 & $(\mathrm{TC}) 8$ & 9 & 1 & 90.0 & 0.86 & 0.27 \\
\hline UBC840 & (GA)8AT & 8 & 0 & 100 & 0.95 & 0.41 \\
\hline Average & & 9.8 & 0.6 & 94.6 & 0.92 & 0.35 \\
\hline
\end{tabular}

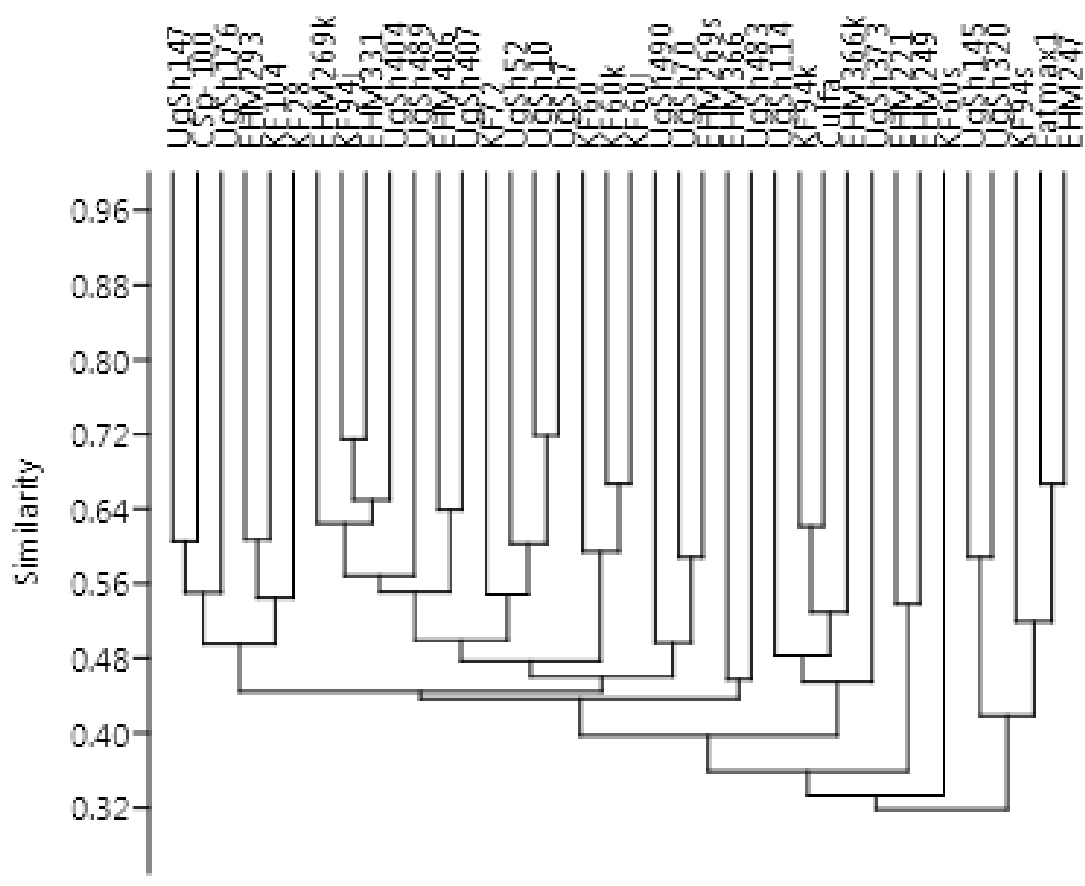

Figure 1. UPGMA dendrogram of 38 maize genotypes based on ISSR marker.

The number and proportion of polymorphic alleles were determined as indicators of genetic polymorphism. The genetic diversity index was calculated using Nei's formula: $\mathrm{H}=1-\sum \mathrm{Pi}^{2}$, where $\mathrm{Pi}$ is the frequency of the ith allele in relation to the total number of alleles (Nei et al., 1974). To establish the effectiveness of the selected marker system, the value of information polymorphism (polymorphism information content), PIC, was calculated (Chesnokov et al., 2015).

\section{Results and discussion}

The genetic diversity of 38 dark-grain maize genotypes was studied using 6 ISSR markers. In general, from among 63, 59 polymorphic alleles $(93.7 \%$ ) were amplified. On average, each locus has 9.8 polymorphic alleles (Table 1).

The length of the synthesized DNA fragments varied within 200-3000 base pairs, depending on the primer. Primer A1 generated an effective marker profile for all maize genotypes. Primer A5 consisting of 6 repeats of the GAA motif revealed the highest number of polymorphic alleles, 16; primers A1 and UBC-823 revealed 11 and 9 polymorphic alleles, respectively; and primer UBC-817 showed the lowest number, 7. All markers used revealed a high level of polymorphism in both hybrids and constant forms, with an average of $94.6 \%$. The genetic diversity index calculated for all primers ranged from 0.86 to 0.95 , with an average of 0.92 . These indicators showed a high level of variability in the genomes of the dark-grain maize samples. Primers A1, UBC-817 and UBC- 840 revealed the highest level (100\%) of genetic polymorphism of the collection studied, while the value of the genetic diversity index was also the highest, $0.95,0.93$ and 0.95 , respectively. For each polymorphic locus, information polymorphism content (PIC) values were calculated (averaged for each primer), 
which were within the range of $0.29-0.41,0.35$ on average. The highest PIC value, 0.41, was detected for primer UBC-840, and the minimum value, for $\mathrm{UBC}-823$. These data make it possible to note the high information content of UBC-840 for the detection of genomic differences and recommend its use in marker selection of maize. Our results of assessing the level of polymorphism generally agree with many studies on the molecular characterization of inbred lines and hybrids of maize using intermicrosatellite markers (Junior et al., 2011; Muhammad et al., 2016). According to the binary matrix of the presence or absence of amplicons with the same molecular weights, a genetic similarity matrix was constructed using the PAST computer program based on the Jaccard index. The coefficient of similarity between pairs of genotypes was in the range from 0.1315 to 0.7187 . The highest coefficient value was found between samples $\mathrm{UgSh} 7$ and $\mathrm{UgSh} 10$, and the lowest similarity was found between genotypes KF94s and UgSh373. These results demonstrate a significant genetic diversity of the studied genotypes of dark-grain forms of maize. Using the cluster analysis based on the UPGMA method, a dendrogram was compiled showing the genetic distances between the maize samples studied (Figure 1).

It shows that the maize samples were grouped in five main clusters. The largest of them - cluster №1 combines 25 genotypes, in turn, divided into 2 subclusters. The first one includes two inbred lines, and the second many-item subcluster combines both hybrids and constant forms. Clusters 2 and 5 included five samples from both categories. Two inbred lines, EHM221 and EHM249, formed Cluster 3. The complex hybrid KF60s has separated as an independent cluster, which indicates a difference in its genetic structure from those of the other forms. The knowledge of the cluster differentiation of the forms studied can be used for crossings in breeding programs. Samples belonging to the same cluster group or subgroup are genetically closer to each other; it is therefore advisable to involve them in crosses in pairs with samples from other clusters, but not among themselves. The distribution of the accessions in five cluster groups confirms significant genetic diversity.

\section{Conclusions}

Being a natural source of food, dark-grain corn with regular inclusion in the diet can contribute to the preservation and improvement of health, due to the presence of anthocyanins (Tsuda, 2012; Petroni et al., 2014; Dolmatova, 2016). In this regard, the selection for increasing the content of useful anthocyanins in the maize grain is relevant.

The study on molecular characterization revealed a significant genetic diversity of 38 inbred lines and dark-grain maize hybrids, adapted to local conditions, from the National Gene Bank of Azerbaijan. High polymorphism values (94.6\%) of PCR products synthesized using six ISSR markers were obtained. The genetic diversity index identified by markers A1, UBC-817 and UBC-840 (0.95, 0.93, and 0.95, respectively) suggests that they are most effective for studying the genetic diversity of maize. Cluster analysis revealed groups of geneti- cally similar and differing samples. For increasing the content of useful anthocyanins in the grain, we identified the forms to be used as a starting material for maize breeding.

\section{References}

Adzhieva V.F., Babak O.G., Shoeva O.Yu., Kilchevsky A.V., Khlestkina E.K. Molecular genetic mechanisms for the formation of the color of fruits and seeds of plants. Vavilovsky Journal Gen Breed. 2015;19(5):561-573. DOI 10.18699/VJ15.073.

Barakat M.N., El-Shafei A.A., Al-Doss A.A. Identification of molecular markers linked to northern corn leaf blight resistance in yellow population of maize genes, genomes and genomics. Global Science Books. 2009;89-95.

Chesnokov Yu.V., Artemeva A.M. Evaluation of the measure of informational polymorphism of genetic diversity. Agricultural Biol. 2015;50(5):571-578.

Dolmatova I.A., Latypova S.Sh. Functional products in the diet of the population. Young Scientist. 2016;7:63-65. URL https://moluch.ru/ archive/111/27940/

Doyle J.J., Doyle J.L. A rapid DNA isolation procedure for small quantities of fresh leaf tissue. Phytochemical Bulletin. 1987;19:11-15.

Fukamachi K., Imada T., Ohshima Y., Xu J., Tsuda H. Purple corn color suppresses Ras protein level and inhibits 7,12-dimethylbenz [a] anthracene-induced mammary carcinogenesis in the rat. Cancer $S c i$. 2008;99:1841-1846. DOI 10.1111/j.1349-7006.2008.00895.x.

Júnior A.T.A., Oliveira E.C., Gonçalves L.S.A., Scapim C.A. et al. Assessment of genetic diversity among maize accessions using inter simple sequence repeats (ISSR) markers. Afr. J. Biotechnol. 2011; 10(69):15462-15469. DOI org/10.5897/AJB10.2624

Khavkin E.E. Molecular plant breeding: DNA technologies for creating new varieties of crops. Agricultural Biol. 2003;3:26-41.

Khlestkina E.K. The adaptive role of flavonoids: emphasis on cereals. Cereal Res. Commun. 2013;41:185-198.

Lago C., Cassani E., Zanzi C., Landoni M., Trovato R., Pilu R. Development of a maize cultivar rich in anthocyanins: colored polenta, a new 133:210-217. doi.org/10.1111/pbr.12153

Muhammad R.W., Qayyum A., Ahmad M.Q., Hamza A., Yousaf M. et al. Characterization of maize genotypes for genetic diversity on the basis of inter simple sequence repeats. Genetics Mol Research. 2017;16(1). DOI 10.4238/gmr16019438.

Nei M., Roychoudhury A.K. Sampling variances of heterozygosity and genetic distance. Genetics. 1974:76:379-390.

Petroni K., Pilu R., Tonelli C. Anthocyanins in corn: a wealth of genes for human health. Planta. 2014;240(5):901-911. DOI 10.1007/ s00425-014-2131-1.

Rodriguez V.M., Soengas P., Landa A., Ordas A., Revilla P. Effekts of selection for color intensity on antioxidant capacity of maize (Zea mays L.). Euphytica. 2013;193:339-345. doi.org/10.1007/s10681013-0924-0.

Salah N., Milad S.I., El-Rouby M.M., Barakat M.N. Identification of new molecular markers of stalk rotary resistance (Fusarium moniliforme) in maize. POJ. 2016;9(1):1836-3644.

Sivolap Yu.M., Trebelsky D.Yu. Identification of maize genotypes using PCR analysis. Cytol Gen. 2001;35(3):14-21.

Tretyakov M.Yu., Khoroshilov S.A., Sidorov A.N., Chulkov A.N., Deineka V.I., Deineka L.A. Corn as a source of anthocyanins. Achievements Sci Technol. 2012;9:30-32.

Tsikov V.S. Corn: technology, hybrids, seeds. Dnipropetrovsk: Dawn, 2003;196.

Tsuda T. Dietary anthocyanin-rich plants: Biochemical Basis Nutriol Food Res. 2012;56:159-170. DOI 10.1002/mnfr.201100526.

Conflict of interest. The authors declare no conflict of interest. 